\title{
COHEN'S RABELAIS
}

by

\section{ERICH GEIRINGER}

THE story of Gargantua and Pantagruel is a literary monument of Humanism, and one of the most amusing books ever written. It is undoubtedly the greatest work of fiction ever produced by a practising physician and its pages abound in references to medical thought and practice of the Renaissance and of the Antique. For these reasons it will always be of peculiar interest to the Medical profession.

A new translation into English, for practical purposes the first after 250 years, ${ }^{*}$ is therefore an important event. The Medical profession is not a very literate one, particularly in the English-speaking countries, and it must be anticipated that thousands of doctors will eventually make their acquaintance with Rabelais through the pages of a translation, especially when it is as racy and readable as that of J. M. Cohen (Penguin r 955 ).

This is by any standard a very good translation. Faced with the formidable task of bridging not only two languages but also four centuries (in which the most revolutionary changes in human thought have taken place) he emerges with a version which does justice to the spirit and style of Rabelais and conveys his authentic message to the contemporary reader.

The curiously unconvincing introduction which prefaces this excellent translation reveals, however, that Cohen, like so many editors and translators before him, has not taken sufficient note of the extent to which Rabelais was writing as a physician; and, scanning the medical passages of the work, one finds a number of misleading renderings. These imperfections, whilst of little importance to the general reader, could give to doctors a rather erroneous idea of the medical thought of Rabelais.

This paper gives a list of these faulty translations together with what I consider the correct version and with the necessary explanations where indicated. Page numbers refer to the 1955 Penguin edition of J. M. Cohen's translation.

\section{FIRST BOOK}

Advice to Readers (p. 36): '. . Rire est le propre de l'homme'. This line which gives the key to the whole work is rendered by Cohen as 'laughter is man's proper lot'. Exigencies of rhyme cannot explain this weak translation because in book V, Chap. 46, Cohen once more translates 'propre' by 'proper lot'. 'Propre', however, is used here as a term of systematic physiology. Rabelais means (with Aristotle) that the ability to laugh is a distinguishing characteristic of man, a property by which man is recognized, just as a bird is by the possession of feathers.

\footnotetext{
*W. F. Smith's translation of 1893 is neither generally available nor very readable. That of J. Le
} Clercq (1936) is an inaccurate free translation more 'Rabelaisian' than Rabelais. 


\section{Erich Geiringer}

To translate this by 'lot' is misleading; indeed, Rabelais is at pains to show that sorrow and tears are unfortunately very often the lot of man. 'Lot', however prefixed, carries with it the connotation of something alloted and lacks therefore the intimate strength of 'propre' which carries with it the meaning of 'Right, privilege, prerogative, distinguishing mark, characteristic'.

Urquart is much nearer the point by translating the line 'laughter is man's property alone'. It may seem pedantic to waste so much space on a shade of meaning but it is unfortunate that this revealing statement of Rabelais's attitude to life, placed by him at the beginning of his book, should be given to our generation in a weakened form.

\section{Prologue}

Page 39: 'cerveau caseiforme' translated as 'cheeselike brain'; caseiforme should probably remain untranslated as a technical term.

Chapter 6, p. 52: 'droict intestine' translated as 'Right intestine'-should, of course, be straight intestine.

Ibid., cotelydons = placenta.

Chapter 14, p. 70: '. . . his said preceptor died. In the year fourteen twenty he caught the pox', should be: '. . . his said preceptor died. In fourteen hundred two and naught $O F$ the pox which he had caught'. N.B. Rabelais took this verse from Marot, changing 1520 to 1420 . No importance attaches therefore to this pre-Columbian case of Syphilis.

Chapter 27, p. 99: 'Reins' translated as 'kidneys' should be back or flanks or loins.

Page Ioo: 'parmi' translated 'on the ballocks' should be through or between the ballocks.

Chapter 35, p. I I5: 'nerf' translated as 'nerve' should be 'sinew'.

Chapter 38, p. 121: 'Chancreuze' translated as 'ulcerous' should be 'chancrous' or 'pocky'.

Chapter 4I, p. I29: for 'cyphos' read 'scyphos' (i.e. not hump but cup or can). Cohen here copies a misprint and then tries to make sense of it.

Chapter 44, p. I 34 : for 'sphagitid' read 'carotid'.

Ibid., for 'temple bone' read 'petrous bone'.

$I b i d$., for 'the posterior lobes of his brain' read 'the two posterior ventricles of his brain'.

This is the first passage in which Cohen translates 'ventricule' by 'lobe'. The same error recurs in Book IV, Chapter 4, where it might give a medical reader the most extravagant notions of Rabelais's knowledge of cerebral localization, and again in Book IV, Chapter $5 \mathrm{I}$, p. 557. There is little justification for this mistranslation especially as Book III, Chapter 4 gives a brief but clear exposition of the Galenical Physiology which held undisputed sway in Rabelais's day and for some time after. According to this physiological doctrine the functions of the mind were performed within the cerebral ventricles by the animal spirits which themselves were the refined, rarefied and subtilized results of the final concoction of the blood by the heart. The cerebral substance itself 


\section{Cohen's Rabelais}

was regarded as little more than a protective and cooling sponge surrounding the all important ventricles.

Chapter 56, p. I58: '. . . give them to certain fine cocks' should read 'give them to certain fine cocks to swallow'.

\section{SEGOND BOOK}

Chapter I, p. I72: 'Canon Bellybag and of Clubfoot, . . .' should remain 'Canon Panzoult and of Piedeboys' as they are probably the names or nicknames of real persons.

Page 173: after 'not having drunk fresh in summer' add 'as reported by Bartachim'.

Chapter 5, p. 182: 'smelt of the suppository', should read 'smelt of the enema'.

In his whole work Rabelais mentions suppositories only once or twice whereas references to enemata ('clysteres') are very numerous. Cohen's translation reverses this proportion (no doubt from a preference for the word suppository) and thus creates a rather misleading impression. The enema ruled supreme in medical practice from the time of Hippocrates and has been losing its hold only within the last generation. It presented an obvious target for those who wanted to poke fun at the medical profession and has provided the inspiration for innumerable jokes throughout the ages as well as for many daring paintings, engravings and even sculptures. The suppository comes a very poor second in all this.

The faulty translation deprives the above passage of most of its point. To smell of a suppository is neither here nor there, but to smell of a (returned) enema provides a fair argument against the study of Medicine.

Chapter 7, p. 192: for 'purge' read 'shittery' or 'shithouse'.

Ibid., for 'suppositories' read 'enemata'.

Ibid., for 'wind-dispeller' read 'fartpuller', or as Le Clercq has it 'poopdrawer'.

Chapter 12, p. 209: for 'decoction' read 'result': for 'garde-robe' read 'commode'.

Chapter 18, p. 232: for 'some quotidian fever' read 'a one day fever' or 'a passing fever'.

Chapter 27, p. 255: for 'smoke' read 'smell'.

\section{THIRD BOOK}

\section{Prologue}

Page 286: 'scurvy' is not in the original.

Chapter I, p. 289: for 'rabbits' read 'locusts'.

Chapter 2, p. 292: for 'hospitals' read 'spittals'.

Chapter 2, p. 294: 'comforts the kidneys, relaxes the vertebrae' should read 'comforts the kidneys, limbers up the loins, decongests the vertebrae'.

Ibid., 'hardens the ballock' should read 'hardens the glans' or as Urquart has it the 'nut'. 


\section{Erich Geiringer}

Chapter 4, p. 300: for 'and shall also support life' read 'and also life'.

Ibid., instead of 'and these two provide' read 'by this I mean'.

Ibid., instead of 'gives warning to shut in the food' read 'tells us to ingest'.

Ibid., for 'mesaraic' read 'mesenteric'.

Ibid., for 'officers' read 'workmen'.

Ibid., for 'renal conduits' read 'renal veins': p. 301 : for 'miraculous network' read 'rete mirabile' or 'choroid plexus'.

Chapter 5, p. 303: for 'mummy oil' read 'mummy'.

Chapter 22, p. 349: instead of 'lice' read 'bugs'.

Ibid., instead of 'tapeworms' read 'worms'.

Ibid., for 'fleshworms' read 'dracunculae'.

Ibid., for 'suppositories' read 'enemata'.

Chapter 27, p. 364 : for 'drug' read 'herb'.

Chapter 31, p. 375: for 'cavernous nerve' read 'cavernous member'.

Chapter 32, p. 379: for 'ventricle' read 'stomach'.

Chapter 34, p. 384: 'rhubarb suppository' (clystere barbarin) is to be understood as an obscene double-entendre without medical significance.

Chapter 42, p. 406: 'may drink harden our livers' is not in the original (and would be startling if it were).

Chapter 45, p. 413: for 'carry a large beaker' read 'carry in their hands a large beaker'.

Chapter 49, p. 422: for 'digest' read 'concoct'.

Chapter 5I, p. 427: for 'bred there by putrefaction' read 'arisen (or generated) there from putrefaction'.

FOURTH BOOK

Dedication to Odet

Page 435: for 'clear cut' read 'clean'.

Ibid., p. 436: for 'disappoint' read 'displease'.

Chapter 4, p. 458: for 'hindmost lobe of my brain' read 'hindmost ventricle of my brain' (which was the place thought to subserve memory).

Chapter I 5, p. 483: for 'forearm' read 'arm'; for 'incisors molars and canines' read 'molars, premolars and canines'.

Chapter I 7, p. 488: for 'the digestive faculties of his stomach naturally accustomed to $a b s o r b$ windmills had not been able completely to assimilate the pots' read 'the concoctive faculties of his stomach naturally accustomed to digest windmills had not been able completely to dissolve the pots'.

Ibid., p. 489: for 'broke his skull' read 'split his brain'.

Ibid., for 'eating a softboiled egg' read 'sucking a softboiled egg'.

Ibid., p. 490: for 'suppositories' read 'enemata'.

Chapter 27, p. 508: for 'he advises the wife, children, etc.' read 'he advises the wife, children, etc., a few days beforehand'.

Chapter 37, p. 529: for 'headaches in one side of the brain' read 'one-sided headaches'.

Chapter 43, p. 54I : for 'oediponic' read 'oedipodic', i.e. swollen footed. 


\section{Cohen's Rabelais}

Chapter 44, p. 543: for 'counter-irritant' read 'counter-poison' (a very different thing), for 'suppository' read 'enema' (suppository made of a concoction makes no sense).

Chapter 5I, p. 557: for 'lobes' read 'ventricles'.

Chapter 54, p. 565: for 'vermillion' (terre sphragitide) read 'terra sigillata', i.e. medicinal clay.

Chapter 63 , pp. 585-6: for 'bagpipes of his stomach' read 'bagpipe of his stomach'.

Chapter 64, pp. 588-9: This list of venomous creatures has been restored by Cohen to something like its proper order after the sometimes incorrect and always misplaced attempts of Motteux to anglicize the original names. But, inexplicably, Cohen omits toads from the list and replaces them by Handled Kettles (!) which are nowhere to be found in the original. He thus perpetuates the mistake of other non-medical editors and translators of regarding this list as a semi-grotesque effort; in reality the list is a bona fide copy by Rabelais of the names of venomous animals from a number of ancient authors and the joke consists merely in its being uncritical and long.

Chapter 66, p. 593: for 'purulent devil' (ladre verd) read 'green leper' or as Motteux has it 'mangy leper'.

Chapter 67, p. 594: for 'the retentive power of the nerve had been relaxed' read 'the retentive power of the nerve had been lost (or paralysed)'.

Chapter 67, p. 595: 'Gracious me, etc.' This passage, which is of special interest to medical readers, emerges somewhat mangled in Cohen's translation. It should read 'How well you are served by Thomas Linacre your learned physician. Knowing that in your old age you would naturally become constipated and that it would become necessary daily to stuff an apothecary-I mean an enema - up your arse to enable you to have your motion. . . ' In Cohen'sversion both the allusion to constipation as a geriatric complaint and the tauntagainst apothecaries are lost. Once more, substitute 'enema' for 'suppository'.

\section{FIFTH BOOK}

Chapter 9, p. 623: 'nerves' (nerfs) should probably read 'tendons'.

Chapter 14, p. 633: for 'digestive tract' read 'belly'.

Chapter 18, p. 644: 'his spleen shook with laughter and he had a colic' should read 'his spleen shook with laughter so that he had a colic'.

Ibid., 'will serve them for borax being salted with nitre and sal-ammoniac in Geber's kitchen' should read 'will serve them for borax, for nitre and for salammoniac in Geber's kitchen'.

Chapter 19, p. 646: for 'quinsy' read 'angina'.

Chapter 2 I, p. 650: after 'Tenes' axe' add 'without solution of continuity'.

Ibid., p. $6_{5}$ I: after 'skin every year' add 'like snakes'.

Chapter 30, p. 675: for 'Juba ... . called them so but Pausanias affirms' read 'Juba ... and Pausanias called them so, but Philostratus affirms'.

Chapter 33, p. 681 : for 'suppository bag' (bourse de clysteres) read 'enema bag', i.e. case to accommodate the enema syringe. 


\section{Erich Geiringer}

Chapter 46, p. 705: for 'proper lot' read 'mark' (distinguishing sign). The last correction is as the first.

Urquart and Motteux's translation of Rabelais avoids most of these errors. Partly this is due to the fact that Galenical Medicine was still in full force in their day (Urquart was a contemporary of Harvey) so that they were under no necessity to try and find contemporary equivalents for the original ideas. Partly it is explained by the dictionary type of translation in which they indulged. Whenever the meaning of a word was doubtful (and often when it was not), Urquart and Motteux simply set down all the meanings which they could find. Barbaric though this may seem it suits the prolific and explicit style of Rabelais quite well and ensures that the correct meaning is always 'among those present'.

Le Clercq's translation uses similar methods and might be called a modern, second-rate, Urquart. It also avoids most of the errors which have been listed here but it is stylistically far removed from the original which it exceeds by about 100,000 words. It bears no comparison with the meticulous and sensitive work of Cohen. It must be admitted however that the latter finds himself occasionally at a loss for the right strong expression, something which never happens to Le Clerq.

It should be stressed that of approximately 500 passages of medical interest incorrect translation was only noted in the above seventy-odd instances, and that a great deal of scholarly endeavour has obviously gone into rendering the remainder correct. Many of these mistranslations are clearly deliberate and have been introduced in the interests of fluency of style or for the sake of approximating obsolete ideas to the mind of a modern reader. Whilst they may thus enhance (superficial) enjoyment their aggregate effect is to give the medical reader a somewhat distorted view of Rabelais's medical thought in particular and of Renaissance Medicine in general. It is to be hoped that some of the corrections, in so far as they do not conflict with the artistic intentions of the translator, may be incorporated in future editions.

\section{ACKNOWLEDGMENTS}

I am grateful to Dr. T. C. Highton for valuable suggestions and for revising the manuscript. 